\title{
Economic research and suggestions on the recycling of waste power batteries for China's new energy vehicles
}

\author{
Li Zhenbiao ${ }^{1, *}$, Li Yuke ${ }^{1}$, Pan Wei ${ }^{1}$ and Wang Jia ${ }^{1}$ \\ ${ }^{1}$ China Automotive Technology \& Research Center Co., Ltd. (CATARC)
}

\begin{abstract}
With the rapid promotion of the number of China's new energy vehicles in promotion and application, it is of great significance to ensure the recycling of the waste power batteries. It can not only effectively reduce the safety and environmental protection risks brought by the waste power battery, but also alleviate China's dependence on rare metals such as cobalt and lithium, which has been widely concerned by the industry. In this paper, the cost analysis model of waste power battery treated by hydrometallurgical process is established, and the economy of recycling of ternary material battery and LFP battery is compared and analysed, and the overall economy of the whole power battery recycling industry is analysed, and the relevant conclusions are obtained, and the relevant suggestions of recycling of power battery are put forward according to the analysis results, to provide reference for industry and related management departments.
\end{abstract}

\section{Overview}

With the continuous increase of the number of China's new energy vehicles in promotion and application, the following waste power batteries are about to enter the period of large-scale decommissioning. If the waste power batteries cannot be properly recycled, it will bring serious safety risks and environmental pollution to the society, and will cause the loss of precious metals such as cobalt and lithium. The recycling of waste power batteries has been widely concerned by the industry.

The recycling of waste power battery refers to the recycling process of the waste power battery for the purpose of recycling valuable elements in the treatment of dismantling, crushing, smelting and so on[1].At present, China's waste power batteries can be divided into two categories: ternary material batteries and lithium-ion ferrous phosphate batteries (LFP).Considering from the technical level, the two categories of waste power batteries can be safely, environmentally friendly and effectively recycled by adopting the technical route dominated by hydrometallurgy process. The technology is mature, the element recycling rate is high, and mature industrialization experience is gained, and Quzhou Huayou, Ganzhou Highpower, Jingmen GEM, Hunan Brunp, Guangzhou GHTECH and other representative recycling enterprises have emerged.

\section{Model construction}

In order to facilitate the quantitative analysis of the recycling economy of different types of waste power batteries, this paper establishes a unified mathematical model of the recycling income of waste power batteries according to the cost analysis method and appropriate simplification [2].

$$
P=I_{t}-C_{d}-C_{i}-C_{t}
$$

Wherein,

$\mathrm{P}$ - profit from recycling of waste power battery;

$I_{t}$ - total income from resource recycling of used power battery;

$C_{d}$ - depreciation cost of waste power battery investment;

$C_{i}$ - cost input for recycling of waste power battery;

$C_{t}$ - tax of waste power battery recycling enterprise.

\section{Determination of values in the model}

\subsection{Confirmation of $I_{t}$ value}

The recycling income of waste power battery mainly comes from the recycling of cobalt, nickel, lithium, aluminium, copper and other metals with high recycling value in the power battery. The following mathematical models can be established to calculate the value of the metals in LFP and ternary battery respectively. It is taken as the total income of the recycling of waste power battery:

$$
I_{t}=\sum P^{*} a^{*} b
$$

Wherein:

$P$ - price of various metals in the power battery;

a-the content of various metals in the power battery;

\footnotetext{
* Corresponding author: lizhenbiao@catarc.ac.cn
} 
b-recycling rate of various metals in power battery.

By referring to the relevant literature and the sales prices of various metals in the current market, the $P$, a and $b$ required for the model are obtained. The specific values are shown below.

Table1. Price, content and recycling rate data of various metals in power battery.

\begin{tabular}{|c|c|c|c|c|c|c|c|}
\hline Metal & Co & Ni & Li & Mn & Fe & Al & Cu \\
\hline $\mathrm{P}^{\mathrm{a}}(\mathrm{RMB} / \mathrm{kg})$ & 274 & 111.50 & 585 & 12.0 & 1.20 & 14.46 & 48.64 \\
\hline $\begin{array}{c}\text { a LFP [3] (mass } \\
\text { fraction) }\end{array}$ & 0 & 0 & $1.10 \%$ & 0 & $7.80 \%$ & $22.7 \%$ & $13.8 \%$ \\
\hline $\begin{array}{c}\text { a Ternary battery [4-5] } \\
\text { (Kg/Kwh) }\end{array}$ & 0.21 & 0.51 & 0.12 & 0.29 & 0 & 2.40 & 1.41 \\
\hline $\mathrm{b}[6-8]$ & $98 \%$ & $98 \%$ & $85 \%$ & $95 \%$ & $90 \%$ & $90 \%$ & $90 \%$ \\
\hline
\end{tabular}

Note: The date in the above table is calculated as NCM (523).

${ }^{a}$ Data source: Data of SMM on August 22, 2019The price of iron comes from https://jiage.cngold.org/c/2018-03-12/c5698123.html

Before 2015, the energy density of China's ternary battery was about $120 \mathrm{Wh} / \mathrm{kg}$, and the energy contained in one ton of ternary batteries was $120 \mathrm{Kwh}$. Combined with Table 1, we can finally calculate the respective incomes of recycling one ton of LFP batteries and one ton of ternary batteries as follows Table 2 .

Table 2. Theoretical calculation income of recycling one ton of LFP batteries and one ton of ternary batteries.

\begin{tabular}{|c|c|c|c|c|}
\hline Metal & $\begin{array}{c}\text { LFP content } \\
(\mathbf{k g})\end{array}$ & $\begin{array}{c}\text { Ternary battery content } \\
(\mathbf{k g})\end{array}$ & $\begin{array}{c}\text { LFP income } \\
(\mathbf{R M B})\end{array}$ & $\begin{array}{c}\text { Ternary battery revenue } \\
\text { (RMB) }\end{array}$ \\
\hline $\mathrm{Co}$ & 0.00 & 24.70 & 0.00 & 6766.70 \\
\hline $\mathrm{Ni}$ & 0.00 & 59.98 & 0.00 & 6687.32 \\
\hline $\mathrm{Li}$ & 9.35 & 12.24 & 5469.75 & 7160.40 \\
\hline $\mathrm{Mn}$ & 0.00 & 33.06 & 0.00 & 396.72 \\
\hline $\mathrm{Fe}$ & 70.20 & 0.00 & 84.24 & 0.00 \\
\hline $\mathrm{Al}$ & 204.30 & 259.20 & 2954.18 & 3748.03 \\
\hline $\mathrm{Co}$ & 124.20 & 152.28 & 6041.09 & 7406.90 \\
\hline \multicolumn{2}{r|}{ Total } & 14549.26 & 32166.08 \\
\hline
\end{tabular}

From the above table, we can get that the expected income from the recycling of one ton of LFP batteries is RMB14, 549.26, and the income from the recycling of 1 ton of ternary batteries is RMB32, 166.08, based on theoretical calculation.

\subsection{Confirmation of $C_{d}$ value}

The average service life method is the simplest and most common calculation method of fixed assets depreciation, which refers to a method of average depreciation based on the service life of fixed assets [9].The calculation formula is shown as follows:

$$
C_{d}=F^{*}(1-S) * 100 \% / L
$$

Wherein:

$F$ - original value of fixed assets, including purchase of equipment, machinery, plant construction, equipment installation and other costs;

$S$-estimated net residual value rate, $5 \%$ in general;

L-estimated service life, 10 years in general.
By querying the total investment, production capacity and other relevant data of various enterprises' resource recycling projects in recent years, we can get the depreciation cost of RMB916 / ton for the investment of equipment and plants on the premise of full utilization of the designed production capacity.

\subsection{Confirmation of $C_{i}$ value}

For the relevant cost input in the recycling process of waste power battery, the model is constructed as follows:

$$
C i=C_{b}+C_{t}+C_{d}+C_{a}+C_{p}+C_{m}+C_{e}+C_{l}+C_{r \& d}
$$

Wherein:

$C_{b}$ - recycling price of waste power battery; It refers to the cost of purchasing waste batteries from a large number of consumers, automobile manufacturers or recycling service outlets by waste power battery resource recycling enterprises. The cost fluctuates greatly with the market, and the recovery price is unstable due to intermediate traders or illegal small workshops bidding up the price. According to the survey, the overall 
average price of the current industry is RMB17, 000 / ton of ternary lithium battery and RMB3, $000 /$ ton of LFP battery.

$C_{t}$ - transportation cost of battery; Waste power battery belongs to Class 9 dangerous goods, which requires high cost for packaging and transportation. There is no standard unit price for the transportation of dangerous goods, According to the survey and calculation, considering the current small amount of waste batteries, each vehicle cannot be fully loaded for operation, RMB1, $000 /$ ton is used for calculation this time.

$C_{d}$ - the cost of physical dismantling and crushing separation of waste power battery; It refers to the cost of dismantling the power battery pack into electrode pieces and crushing and sorting the electrode pieces by the waste power battery recycling enterprise;

$C_{a}$ - cost of chemical materials for hydrometallurgy; It refers to the cost of various chemical materials to be added in the hydrometallurgical process of waste power battery, such as $\mathrm{H}_{2} \mathrm{SO}_{4}(98 \%)$, $\mathrm{HCL}(30 \%)$, $\mathrm{NaOH}(30 \%)$, $\mathrm{Na}_{2} \mathrm{CO}_{3}$, P507 extractant, P204 extractant, kerosene, $\mathrm{H} 2 \mathrm{O} 2$, water, manganese sulfate, etc.;

$C_{p}$ - fuel power cost; It refers to the cost of electricity, natural gas, etc. required in the process of resource-based processing, and the cost of fuel and power (such as heating, lighting, etc.) necessary to maintain the normal operation of the enterprise;

$C_{m}$ - equipment maintenance cost;

$C_{e}$ - environmental protection input cost; For the cost of harmless disposal of waste gas, waste liquid and residue in the process of waste power battery resource recycling, the expenditure is relatively high;

$C_{l}$ - labour cost;

$C_{r \& d}--\mathrm{R} \& \mathrm{D}$ cost. In order to adapt to the recycling of different types of power batteries, maintain the production efficiency of the enterprise, and realize the continuous improvement of resource utilization, this part of the cost is also indispensable. According to the requirements of China's high-tech enterprises, it is calculated according to $3 \%$ of the sales revenue.

\subsection{1 $C_{i}$ of ternary material battery}

According to Formula (4), the industry investigation and collection of relevant costs in the resource recycling process of ternary material battery are carried out, which are shown in Table 3 after sorting out. When the power battery recycling equipment is utilized in full capacity, the cost of handling one ton of waste ternary material battery is the lowest, about: RMB28, 193.08.

Table3. $C_{i}$ of waste ternary material battery.

\begin{tabular}{|c|c|}
\hline Name & Cost (RMB) \\
\hline$C_{b}$ & 17000 \\
\hline$C_{t}$ & 1000 \\
\hline$C_{d}$ & 3250 \\
\hline$C_{a}$ & 2696.80 \\
\hline$C_{p}$ & $1341 . .3$ \\
\hline$C_{m}$ & 120 \\
\hline
\end{tabular}

\begin{tabular}{|c|c|}
\hline$C_{e}$ & 320 \\
\hline$C_{l}$ & 1500 \\
\hline$C_{r \& d}$ & 964.98 \\
\hline$C_{i}$ & 28193.08 \\
\hline
\end{tabular}

\subsubsection{Ci of LFP battery}

According to Formula (4), investigation and collection of the relevant costs are carried out, as shown in Table 4 after sorting out. When the power battery recycling equipment is utilized in full capacity, the cost of processing one ton of waste LFP battery is the lowest, about: RMB12, 308.48 .

Table4. $C i$ of waste LFP battery.

\begin{tabular}{|c|c|}
\hline Name & Cost (RMB) \\
\hline$C_{b}$ & 3000 \\
\hline$C_{t}$ & 1000 \\
\hline$C_{d}$ & 3250 \\
\hline$C_{a}$ & 1180 \\
\hline$C_{p}$ & 1502 \\
\hline$C_{m}$ & 120 \\
\hline$C_{e}$ & 320 \\
\hline$C_{l}$ & 1500 \\
\hline$C_{r \& d}$ & 436.48 \\
\hline$C_{i}$ & $\mathbf{1 2 3 0 8 . 4 8}$ \\
\hline
\end{tabular}

\subsection{Confirmation of $C_{t}$ value}

The types of taxes that need to be paid by resource recycling enterprises include value-added tax, urban construction tax, education surcharge, local education surtax and income tax and other relevant entries. For power battery resource recycling enterprises, whether there is input tax or not has a great impact on the valueadded tax that enterprises should pay. The details are shown in the following Table 5:

Table 5. Tax payable by enterprises $C_{t}$.

\begin{tabular}{|c|c|c|}
\hline $\begin{array}{c}\text { Whether there is input tax } \\
\text { deduction when recycling } \\
\text { waste batteries }\end{array}$ & \multicolumn{2}{|c|}{ Total tax amount } \\
\cline { 2 - 3 } & $\begin{array}{c}\text { Ternary } \\
\text { battery }\end{array}$ & $\begin{array}{c}\text { LFP } \\
\text { battery }\end{array}$ \\
\hline No deduction & 3279.36 & 873.51 \\
\hline All deduction & 1147.59 & 497.32 \\
\hline Half deduction & 1821.50 & 445.22 \\
\hline
\end{tabular}

It can be seen from the above Table 5 that there is a difference of about RMB 2,131.77 in the tax payable for recycling one ton of ternary material batteries between whether there is the input tax invoice or not. In terms of the tax amount per ton of LFP battery, there is not much difference between whether there is input tax invoice or not, but if the recycling volume is large, there will be a big gap in the tax payable.

At present, it is difficult for enterprises in the industry to obtain input tax invoices. Therefore, the 
theoretical calculation is carried out temporarily based on half deduction.

\section{Economic analysis}

\subsection{Economic analysis of single enterprise}

The above calculated and determined values are brought into Formula (1), and the economic analysis of one ton of ternary material batteries and LFP batteries are sorted out as shown in Table 6 below.

Table 6. Economic analysis of waste ternary materials and LFP battery recycling.

\begin{tabular}{|c|c|c|}
\hline Item & Ternary battery & LFP battery \\
\hline$I_{t}$ & 32166.08 & 14549.26 \\
\hline$C_{d}$ & 916 & 916 \\
\hline$C_{i}$ & 28193.08 & 12308.48 \\
\hline$C_{t}$ & 1821.50 & 445.22 \\
\hline$P$ & 1235.5 & 879.56 \\
\hline
\end{tabular}

It can be seen from the above table: Under the condition of full capacity operation of the equipment, the enterprise can make profits by recycling ternary materials and LFP battery. A profit of RMB1, 235.5 can be made by recycling one ton of ternary material batteries, and a profit of RMB879.56 can be made by recycling one ton of LFP batteries.

For a single recycling enterprise, the premise of the enterprise's profitability, regardless of ternary material battery or LFP battery, is the full capacity operation of the enterprise's design capacity. Through calculation, it is found that the enterprise's capacity utilization ratio at the break-even point is at least $42.58 \%$ for the ternary material battery to ensure the balance of revenue and expenditure; For the LFP battery, when the capacity utilization rate is at least $51.01 \%$, the balance of revenue and expenditure can be guaranteed. At present, the capacity utilization rate of typical recycling enterprises in China is less than 5\%, and all enterprises are in the state of loss, only considering the recovery of waste power batteries.

\subsection{Economic analysis of the whole industry}

The whole power battery resource recycling industry is regarded as an enterprise to analyse its economy. According to the incomplete statistics of the current overall capacity of the recycling industry, by the end of 2018, the industry has formed a capacity of 427,500 tons[11], while the theoretical decommissioning volume of the power battery in 2018 is 47,500 tons (the actual recovery of the power battery by typical enterprises is less), the overall capacity utilization rate of the industry is only $11.11 \%$, and the industry is in a state of loss.

In 2020, the whole industry of recycling will form a capacity of $1,261,500$ tons, while the theoretical predictive decommissioning volume of the power battery in 2020 is 140,900 tons, the overall capacity utilization rate of the industry is only $11.17 \%$, and the industry is still in a state of loss.

In 2025 , the overall capacity of the industry is calculated according to $1,261,500$ tons in 2020. The estimated decommissioning volume of the power battery in 2025 is 420,900 tons, and the overall capacity utilization rate of the industry is $33 \%$, and the industry is still in a loss state.

For the whole recycling industry of waste power battery in China, it will be in a loss state in the next few years. The industry is in an overheated trend generally. At present, there are still many enterprises and capital actively entering the resource recycling industry of power battery, which may make the overcapacity of the whole industry more serious.

\section{Suggestions and prospects}

\subsection{Suggestions}

Through the analysis of the income and cost in the whole model, we can find that the profit from power battery recycling fluctuates with the price of rare metals. In several cost outputs, the price of waste power battery, transportation cost and whether there is input tax invoice deduction have a great impact on the profit of the enterprise. Based on the above analysis, suggestions are provided as follows:

First, speed up the construction of standardized and efficient recycling system for waste power batteries. Establish a unified and standardized market pricing mechanism and industry self-discipline mechanism for the recycling of waste power batteries, continue to strengthen the fight against illegal recycling channels, and control the price fluctuation of waste power batteries within a reasonable range. At present, the phenomenon of illegal vendors competing for the source of goods by illegally driving up the price of waste power batteries is extremely unfavourable to the orderly and healthy development of China's waste power battery resource recycling industry.

Second, it is suggested that on the basis of in-depth study, the relevant departments formulate the relevant policies that the waste power battery meeting relevant conditions can be exempted from transportation according to general goods through the demonstration of the corresponding packaging scheme, reducing the high cost of the transportation of waste power battery.

Third, it is suggested that relevant departments research and formulate targeted tax preferential policies to reduce the tax burden of enterprises engaged in waste power battery resource recycling, such as: Revise and improve the Preferential Catalogue of Value Added Tax on Products and Labour Services for Comprehensive Utilization of Resources (CS [2015] No. 78), include the enterprises for recycling of waste power batteries into the scope of tax preferential policies, adjust the existing relevant requirements for waste batteries and their dismantling materials, and increase the relevant contents for recycling lithium metal and its compounds and recycled graphite anode, etc. Or the recycling of waste 
battery goods is subject to the scope of preferential policies of value-added tax levied by simple methods.
Vehicle Power Batteries [J]. Resource Recycling, 2018 (09): 34-36.

\subsection{Prospects}

In this paper, only the waste power battery industry is considered in the economic analysis of recycling of enterprises and industries, but the decommissioning volume of consumer class $3 \mathrm{C}$ lithium-ion battery is not taken into account. After taking it into account, further research and analysis will be carried out.

\section{Acknowledgement}

This work was supported by National Key Research and Development Program of China Solid Waste Resource Utilization Special Project Power Battery Full-life Cycle Value Chain Ecological Coupling Mode Research (2018YFC1902205).

\section{References}

1. Technical policy for recycling of electric vehicle power battery (Edition 2015) (No. 2 in 2016)

2. Li Yuke, Guo Miao, Yan Ao. Study on the Economy of Vehicle Power Battery Recycling [J]. Automobile \& Parts, 2014 (24): 48-51.

3. Yu Haijun, XieYinghao, Zhang Tongzhu. Progress in Recycling Technology of Vehicle Power Battery [J]. The Chinese Journal of Nonferrous Metals, 2014, 24 (02): 448-460.

4. Wang Weidong, QiuWeihua, Ding Qianqian. Process Technology and Production Application of Ternary Materials for Lithium-ion Batteries [M]. Beijing: Chemical Industry Press, 2015, 14

5. Yin Renshu, Yang Yanping, XieLinming, Chen Zhilin, Chen Yuanhua. Demand Forecast of New Energy Vehicle Power Battery for Non-ferrous Metal Resources [J]. Resources \& Industries, 2016, 18 (05): 85-91.

6. GB/T 33059-2016 Methods for Disposal and Recycling of Lithium Ion Battery Material Wastes

7. HG/ T 5019-2016 Recycling Method of Nickel and Cobalt from Waste Batteries

8. Industry Standard Conditions for Comprehensive Utilization of Waste Power Batteries for New Energy Vehicles (Announcement [2019] No.6 issued by the Ministry of Industry and Information Technology)

9. Tang Jianwei. Selection of Depreciation Policy for Fixed assets [J]. Value Engineering, 2019, 38 (18): 80-82.

10. Li Hongxuan. A Brief Analysis on How to Choose Depreciation Policy Scientifically and Reasonably [J]. Guide to Business, 2012 (17): 97-98.

11. Li Zhenbiao, Li Yuke. Forecast of the Decommissioning Volume of China's New Energy 